\title{
Revisitando el Radiodrama en la Actualidad
}

\section{Revisiting the Radiodrama today}

\author{
Francisco Godinez Galay \\ Director del Centro de Producciones Radiofónicas del CEPPAS. \\ francisco@cpr.org.ar
}

Resumen

El radiodrama es una familia de géneros que utilizan los elementos del lenguaje radiofónico para contar historias. No solo se trata de radioteatro y no solo se habla del pasado. Las distintas formas del radiodrama se resignifican en el presente, con nuevos roles y nuevas posibilidades. Sus características técnicas, narrativas y subjetivas, se suman a las potencialidades que brindan las tecnologías de la información y la comunicación. Hoy existen en América Latina ejemplos que confirman que es posible producir contenidos innovadores, creativos, entretenidos, que consideren a las TIC como una herramienta a favor, y que contemplen sus roles sociales y la producción independiente. Estas experiencias permiten augurar un futuro promisorio para el género y una nueva época para la radio. Reflexionaremos sobre sus características y alcances.

Abstrac Radiodrama is a family of genres that uses radio language elements for storytelling. We don't talk only about radioplays, or about the past. Today, the many forms of radiodrama got new roles and new posibilities. This article is about its techniques, narratives and particular characteristics, in addition to the potential offered by information and communication technologies. Nowadays in Latin America there are many examples confirming that it is possible to produce innovative, creative and entertaining content, which use ICT as a tool to foster production posibilities, and which contemplates its social role and independent production. These experiences foretell a promising future for the genre and a new era for the radio. Here we will reflect on this gender, its characteristics and scope.

\footnotetext{
Palabras

Radiodrama, radioteatro, TIC, nuevas narrativas, América Latina

Clave

Key Radiodrama, radiotheater, ICT, new narratives, Latin America

Words
} 


\section{Introducción}

¿De qué hablamos cuando hablamos de radiodrama? En este artículo delinearemos una definición del radiodrama, así como las características y las distintas formas que adopta, tanto en lo que respecta a sus aspectos técnicos, narrativos y subjetivos. Veremos que el radiodrama es la materialización de una de las características centrales de la radio, la que llamamos doble apelación razón-emoción.

Además, revisaremos la actualidad, nuevas utilidades y potencialidades del radiodrama, sobre todo como herramienta no solo de entretenimiento, sino para contar la realidad y temas de interés social, educativo y cultural. En esta intención de reflexionar sobre la actualidad del género, revisaremos sus relaciones con las tecnologías de la información y la comunicación, las nuevas plataformas y las nuevas formas de creación y lectura que las TIC habilitan.

Por último, haremos un repaso sobre algunos casos que creemos que ejemplifican bien los distintos aspectos de lo expuesto, en cuanto a las nuevas formas del género en la actualidad y sus posibles roles en América Latina.

\section{Características y tipos}

\section{1) Características concretas.}

Para empezar a ubicarnos de mayor a menor, diremos que una primera aproximación a una definición del radiodrama nos indica que se trata de ficción en radio. De allí en más se abre una enorme serie de posibilidades expresivas, que tienen en común el hecho de utilizar los elementos del lenguaje radiofónico para contar historias de ficción (incluidas las ficciones sobre la realidad).

Los elementos del lenguaje radiofónico son cuatro y son los colores primarios de la radio: con sus distintas formas y combinaciones, se puede crear cualquier contenido plausible de ser transmitido por radio y extendido, como veremos, a las plataformas digitales. Se trata de la voz, la música, los sonidos y el silencio.

Si tenemos que mencionar características generales de las distintas formas del radiodrama, deberíamos mencionar la presencia de una estructura narrativa (introducción-nudo- 
desenlace), un conflicto, personajes, acciones, escenas. Y todo ello expresado con sonidos (Godinez, 2011).

Como veremos en el desarrollo del presente texto, lo que distingue al radiodrama de otros modos de contar historias es su fuerza para potenciar la imaginación, ya que la falta de anclaje con imágenes visuales genera tantas lecturas como oyentes existan, gracias a que la clausura de interpretaciones es más flexible que en otros medios. Aquí, si bien hay cierta cantidad de "lecturas preferentes", hay una diversidad de posibles decodificaciones, no presente en otro tipo de medio (Hall, 1994). Asimismo, el radiodrama tiene la capacidad de comunicar no solo conceptos, sino también emociones y sentimientos como ningún otro género y como en ningún otro soporte.

\section{2) Tipos de radiodrama.}

Revisemos brevemente qué formas puede adquirir el género dramático en radio. Nos interesa particularmente abordar esta resumida caracterización de los subgéneros para dimensionar el abanico de posibilidades narrativas que hay dentro de la familia del radiodrama. Esto, a su vez, nos permite delinear un escenario actual en que las posibilidades tecnológicas no estarían al servicio de un compartimento pequeño como puede parecer, a priori, el radioteatro. Si entendemos que radiodrama es mucho más que radioteatro, y comprendemos qué formas adquiere, podremos pensar mejor en sus potenciales usos con fines que exceden el mero entretenimiento, a la vez que podremos pensar relaciones más ricas con la tecnología.

a) Radioteatro. Historia radiofónica que empieza y termina en una misma emisión. Personajes -y casi siempre un narrador- llevan adelante las acciones que son presenciadas por el oyente a través del oído. Las duraciones varían (volveremos sobre esto en nuestra referencia sobre la actualidad), pero puede tratarse de obras integrales de entre media hora y una hora.

b) Radionovela. Muchas veces usado como sinónimo de radioteatro, pero que en rigor de la verdad, se trata de una historia contada a través de capítulos, cuyas entregas pueden ser diarias o semanales. Las acciones se continúan de emisión a emisión.

c) Radioserie. Una serie radiofónica se puede ubicar entre el radioteatro y la radionovela. Tiene sutiles diferencias con ellos: si bien se trata de una historia con varios capítulos, cada capítulo es una historia en sí misma que empieza y termina. 
d) Monólogo. Historia contada, casi siempre en primera persona, por un personaje que se dirige a un interlocutor imaginario o al oyente como interlocutor. Es una sola voz narrando lo que le sucede o que siente, haciendo una reflexión interior, o recuperando un pasado vivido a partir de su relato.

e) Sketch. Historia casi siempre de humor, que suele ser corta, de pocos personajes sin el diseño integral que requieren los personajes del radioteatro, y que puede prestarse para la improvisación sobre un mínimo eje predefinido.

f) Personaje. Se trata de la posibilidad de que un personaje radiofónico de ficción interactúe con "personas reales" en un contexto radiofónico no ficcional, como puede ser un magazine radiofónico o incluso un programa informativo.

g) Recreación y dramatización. Estas formas hermanas suelen ser utilizadas dentro de contenidos periodísticos, informativos o documentales. Es una herramienta que permite ilustrar un contenido que trate alguna temática o problemática de la actualidad, la cultura o la historia. La ficción termina sirviendo como ejemplo de algo que se narra, a la vez que permite descansar el oído y brindar informaciones y opiniones de forma estética y dinámica.

La diferencia entre ambas radica en que, en el caso de la recreación, se trata de la puesta en sonidos de algo que ocurrió tal como se relata; mientras, la dramatización ilustra la forma típica en que determinado tipo de cuestiones suelen o pueden darse en la realidad, pero no describe un caso puntual.

h) Sociodrama. Este concepto, asociado a la radio con fines de educación popular, fue impulsado sobre todo por radialistas como Mario Kaplún o José Ignacio López Vigil (1997). Refiere a la utilización del radiodrama con fines sociales, educativos y emancipatorios. En su concepción, solía tratarse de radioseries o radionovelas, y su diferencia radica en los objetivos temáticos para los cuales se produce. También, en lo formal, el sociodrama abre dos posibilidades: que sea creado e interpretado por la comunidad, lo que la pone en un rol activo en la reivindicación de sus luchas sociales; y que exista un feedback con el oyente, a través de la implementación de instancias posteriores al relato que sirvan como espacio de debate, opinión o acción. Un ejemplo paradigmático es el célebre Jurado Número 13 de Mario Kaplún. En este sociodrama se presentaba alguna problemática social en forma de caso judicial, en el que, justamente, el oyente era el jurado número 13 y tenía capacidad de reflexión. 
i) Radioarte. Podríamos definir al radioarte como la familia de todas las formas de la experimentación sonora y la expresión estética radiofónica; o en palabras de Lidia Camacho, "la posibilidad (...) de tratar el sonido de manera artística, en sí mismo y no sólo en sentido musical" (Camacho, 2007, p. 126).

j) Poesía y cuento adaptados o sonorizados. Cuando se toma un poema o un cuento con la intención de hacer su adaptación al soporte radiofónico, existen al menos dos grandes opciones. Por un lado, la simple lectura de la obra literaria, y el agregado de efectos sonoros y música. Por otro, hacer una traducción al lenguaje radiofónico, no una mera traslación de un texto al sonido. La traducción implica la comprensión de las especificidades del lenguaje de la radio, y la explotación de sus posibilidades.

k) Radiofilm. Hablamos de radiofilm cuando estamos ante un contenido que si bien puede clasificarse como radioteatro, contiene ciertas referencias al lenguaje cinematográfico y está estructurado como una película. Por un lado, es de larga extensión. Por otro, la presencia de escenas y acciones sin palabras, como puede suceder en el cine. En este sentido, contiene necesariamente experimentación sonora. Por último, la presencia tanto de elementos del lenguaje cinematográfico (juegos de "cámaras") como de clichés del cine.

I) Radiocómic. Nos referimos a radiocómic cuando una historia (generalmente radioteatros cortos y veloces) es expresada mediante la traducción sonora de algunos clichés o señas del género cómic. De este modo, elementos como la estructura de viñetas, las onomatopeyas, la caricaturización de los personajes, la velocidad, el color, y hasta el trazo, pueden reinterpretarse a partir de los sonidos agregados o los tonos y timbres de las voces, dando origen a un radiodrama con una estética propia muy reconocible.

Como estas formas, se podrán encontrar más. La idea es ver la multiplicidad creativa que puede dar un concepto tan amplio como el de radiodrama. $Y$, sobre todo, cómo podemos escapar al concepto de radioteatro como único posible, lo que nos depositará directamente en una actualidad diversa y en un futuro lleno de potencialidades para el medio radiofónico y sus roles. A su vez, es importante tener en cuenta estas clasificaciones porque "La ciberradio asume en gran parte los géneros tradicionales de la radio, pero les somete a tales cambios que cobran otras dimensiones, amplían su campo de acción e incluso se generan otros nuevos" (Cebrián, 2008, p. 84). 


\section{Nuevos roles y nuevas formas.}

\section{1) Los roles del radiodrama en la actualidad.}

El radiodrama en la actualidad resurge resignificado respecto del auge de la época de oro del radioteatro y la radionovela. Si antes se trataba de entretener y divertir, y en algunos casos culturizar en el peor sentido de la palabra, hoy el radiodrama se abre a posibilidades sociales, políticas, educativas y culturales muy interesantes. Si bien muchas experiencias ya lo manifiestan, es un terreno amplio lleno de potencialidades que explorar.

No es que no existieran experiencias de este tipo en el pasado. De hecho, los sociodramas de productores como Mario Kaplún o José Ignacio López Vigil, existen desde los años 60 hasta el presente, y toman las herramientas de la ficción para relatar problemáticas sociales en América Latina, sensibilizar y llamar a la acción para el cambio social'1.

El radiodrama, que surge a la par de la radio, tuvo su protagonismo hasta los años 60, con énfasis en el entretenimiento. Con el advenimiento de la televisión, la fascinación por el nuevo soporte hizo que la ficción pasara a la pantalla, y la radio quedara encargada de la información y la música: "Las claves de la década fueron los avances tecnológicos y la transformación provocada por la competencia de la televisión (...). Ambos aspectos se relacionan con el nacimiento de una nueva radio, que apoyó sus mensajes en dos pilares principales: la música y la información" (Ulanovsky, 2004, p. 13). El fenómeno que se evidencia desde comienzos del siglo XXI es el reencuentro con las variedades del radiodrama, pero resignificadas tanto en sus formas (formatos cortos, influencia de las TIC, narrativas transmedia, mayor experimentación sonora), como en sus temas y roles (hoy aparece como una posibilidad para contar temáticas y problemáticas de la realidad; para contar la Historia; para ser expresión popular para el descontento por la iniquidad; para la lucha por el cambio social y el fortalecimiento de los Derechos Humanos a través de campañas de bien público; o como contenidos educativos y culturales)

Para comprender mejor las posibilidades y funciones actuales del radiodrama en cuanto a su rol social, es menester que además de haber revisado sus características técnicas y formales, nos dediquemos a reflexionar sobre lo que llamaremos sus características emocionales o subjetivas.

1 Algunos ejemplos son el mencionado Jurado Número 13, Un Tal Jesús, 500 Eng-años, Noticias de Última Ira. 


\section{2) Características emocionales o subjetivas del radiodrama.}

Para saber qué es el radiodrama y cuáles son sus usos y posibilidades en la actualidad, no podemos dejar de lado sus características emocionales, esto es, sus efectos, impactos o lecturas en la persona individual y en la persona social. El radiodrama encarna como ningún otro género algunas características del soporte radiofónico:

a) Imaginación. El radiodrama potencia la imaginación. El hecho de no poseer imagen (imagen visual, aunque sí imágenes sonoras), no es una carencia, sino una virtud de la radio; virtud que se desarrolla mejor a través del radiodrama. Un oyente imagina lo que escucha de un modo que será distinto al que imaginen otros oyentes.

b) Creatividad. Desprendido de lo anterior, el radiodrama potencia la creatividad, en dos sentidos. Por un lado -lo decíamos-, del oyente. El oyente pone de sí mismo en la recepción de ese mensaje, que deja de ser tan pasiva como en otros medios o en otros géneros del medio radiofónico. La historia se completa en cada auditor, y es necesariamente distinta para cada persona. De este modo, se genera una implicación más proactiva del oyente, y por lo tanto, creativa.

Y por otro lado, también favorece la creatividad del autor, ya que basándose en los cuatro elementos del lenguaje radiofónico, puede contar cualquier historia: "Si bien en la radio los elementos son cuatro, siempre hay algo nuevo. Porque la imaginación no tiene límites. (...) Se puede tener la mejor tecnología, pero si no está la imaginación y la creatividad, de nada sirve" (Holgado, 2013, p. 22). Es por eso que nos interesan no solo las nuevas posibilidades técnicas, sino la variedad narrativa sobre la que esas tecnologías vienen a intervenir, y los potenciales nuevos resultados que surjan de esa relación. Y por eso es que vemos importante conocer los distintos tipos de radiodrama, para luego ponerlos a funcionar con las actuales necesidades y oportunidades.

c) Identificación. Somos seres sociales; y lo somos gracias a que tenemos una sofisticada herramienta de comunicación: el lenguaje. Y esa comunicación es, en gran parte, sonido, "sin el cual no existiría el lenguaje oral y por lo tanto la comunicación humana como la conocemos" (Larson, 2012, p. 69): "La escucha no sólo es una cuestión de psicología individual, sino de inserción social" (Castañeda, 2011, p. 78). La preponderancia de la imagen visual es relativamente nueva en la historia de la cultura humana. El sentido de la intimidad, de la cercanía, de la confianza, de la ubicación, y hasta del equilibrio, es el 
oído. Este sentido está muy asociado a la seguridad y a la autorrealización de nosotros como seres humanos en un contexto. Por eso confiamos en el oído: "El oído no es meramente un amplificador o altoparlante (...) Está conformado por un proceso milenario de selección natural para protegernos del peligro, y para que podamos alimentarnos y reproducirnos" (Castañeda, 2011, pp. 29-30). Esto hace que la inmersión a una historia a través del oído, genere mucha más fidelidad al contenido, y por ende al tema.

El efecto no será el mismo cuando un narrador nos cuente en un informe periodístico el sufrimiento de los niños pobres de nuestra región, que cuando escuchemos -y vivamosese sufrimiento como testigos de una ficción sonora que lo relate. Quedamos desnudos de protección frente al mensaje, nos imbuimos en él, nos identificamos con esas voces que encarnan vidas posibles. El sonido nos inunda, nos rodea, nos brinda información desde el lugar de la confianza y nos modifica: "Nuestras reacciones internas también forman parte de la escucha" (Castañeda, 2011, p. 45).

d) Doble apelación razón-emoción. Por último, el radiodrama actual ha comprendido la función del sonido para comunicar sensaciones. La voz ya no es la protagonista de las historias. La música, el sonido y el silencio, aparecen fortalecidos cumpliendo roles narrativos imprescindibles.

La doble apelación hace referencia a que con la radio en general, y con el radiodrama en particular (sobre todo en la actualidad), podemos comunicar conceptos, textos, palabras, temas concretos, información, que son vehiculizados a través de las voces de los personajes. Pero también sensaciones, emociones, sentimientos, a través de las elecciones sonoras, las músicas, e incluso las sonoridades de las voces (la voz no solo es transmisión de textos). “(...) El cerebro nos ofrece en milésimas de segundo una imagen mental de la fuente del sonido y una determinada emoción frente a ella" (López Vigil, 1997, p. 36). Con el radiodrama podemos contar lo dura que puede resultar una tragedia como un terremoto, a través de lo que cuentan los personajes. Pero esa angustia la podemos comunicar, reforzar o ilustrar a través del sonido, que no le habla a la razón, sino directamente al cuerpo. El cuerpo tiene su lógica propia para asir el mundo, distinta que la de la razón (Merleau-Ponty, 1957). Antes de que podamos racionalizar que una música es correcta, que está bien ejecutada o que tiene una estructura lógica o simétrica, la música nos gusta o no nos gusta, nos emociona o no, y hasta puede provocarnos reacciones físicas como erizarnos la piel. 
En resumen, la experimentación y la planificación sono-narrativas hacen que en la actualidad el radiodrama maximice su responsabilidad y efectividad desde su rol social.

\section{3) Las TIC nos atraviesan.}

Describir la actualidad del radiodrama implica necesariamente hacer una referencia a la presencia transversal que tienen las tecnologías de la información y la comunicación en la vida cotidiana. Y precisamente, la actualidad de un género como el radiodrama, no solo no es ajena a esta realidad, sino que se realimenta y resignifica a partir de ella.

a) Internet como caja de recursos. Por un lado, Internet ofrece múltiples posibilidades a productores, tanto para acercarse a información sobre el género, como a temáticas que abordar y materiales que utilizar. Internet es un gran repositorio de músicas, efectos sonoros, audios históricos, información y contactos, que pueden usarse en cualquier producción o inspirarnos.

b) Las TIC potencian la producción. También, las TIC tienen la potencialidad de facilitar, abaratar y agilizar la producción.

c) Las TIC democratizan la posibilidad de expresar. Internet también sirve para generar mejores condiciones para que no solo sean las emisoras de gran presupuesto quienes puedan producir y publicar sus contenidos. Hoy hacen posible que radios comunitarias o productores independientes produzcan y publiquen aumentando las posibilidades creativas y de recepción que antaño estaban reservadas solo para unos pocos.

d) Producir pensando en las TIC. Además de estas oportunidades, las TIC generan desafíos para la producción actual, y concretamente para el radiodrama. Hoy navegamos por un mar de información y contenidos en el cual hay que destacarse. ¿O solo importa que podamos publicar, sin importar si alguien nos escucha? Detengámonos en este punto. Por un lado, es fundamental poder expresar lo que sea en la plataforma que sea, y la Internet aumenta las posibilidades de expresión efectiva de quienes siempre tuvieron voz, pero pocas veces micrófono: hoy el micrófono está más al alcance de la mano. Y el solo hecho de poder hacerlo, de expresar algo, tiene una importante función relacionada con la autorrealización y la autoidentificación. Pero si queremos explorar la otra cara de la moneda de la comunicación, nos interesará no solo publicar, sino además que nos escuchen. Porque como decíamos oportunamente "los conceptos de información y 
de expresión son de una sola vía. Tenemos derecho a recibir datos. Tenemos derecho a emitir. No importa qué pase del otro lado. Y esto no tiene mucho de comunicativo" (Godinez Galay y Binder, 2012, p. 2). Pues bien, las TIC hoy nos dan más herramientas para que la interlocución sea posible.

Pero hay un punto sobre el que aún debemos reflexionar. Hoy debemos pensar en que las TIC ensanchan las posibilidades de escucha de nuestro contenido, pero si tenemos en cuenta que hoy debemos "producir pensando en Internet (...); combinar y equilibrar la producción al aire con la producción para la nube (...); (considerar) las narrativas transmedia, multigénero y multisoporte (...); y retomar viejos y olvidados géneros y actualizarlos" (Godinez Galay, 2014, p. 3), tenemos que saber que el radiodrama debe adaptarse a la época que describe Piscitelli:

Estamos viendo una multiplicación de autores; estamos viendo multiplicación de formatos; estamos viendo multiplicación de posibilidades comunicativas; estamos viendo también la invención de nuevas instituciones y organizaciones. Todas creadas o en vías de gestación, tratando de superar las limitaciones del paradigma del broadcast. (Piscitelli, 2011, p. 72)

Así, produciremos para transmitir por onda hertziana, pero también para publicar en Internet. Nos interesa esa posibilidad de multiplicar la divulgación que la Internet ofrece. Pero nos interesa que sea bien aprovechada. Hoy el radiodrama se expresa en contenidos de una hora de duración -como antaño-, aquellos pensados para su transmisión por radio, pero también para descargarse de la web y dedicarles un lugar especial en la rutina diaria. En este sentido, debemos pensar que en la producción actual, el radiodrama debe flexibilizarse.

Entonces, el radiodrama en la actualidad considera también historias que son resueltas en poco tiempo (de 3 a 10 minutos), y que sean ágiles. Asimismo, no renuncia a esas versiones largas de media hora o una hora, pero se piensa también en su publicación en distintas versiones. Esa historia de una hora, se publica entera en un solo archivo; pero también se publica en partes más cortas, en capítulos. Se debe pensar desde la instancia de guionado en estas necesidades de flexibilidad y de ofrecer múltiples formatos. En Internet debemos pensar en que los contenidos sean fáciles de manejar en todo sentido. Los productores del radiodrama de hoy, tienen que pensar en estas nuevas características de publicación y escucha. Y los ejemplos en este sentido empiezan a proliferar. 
Esta posibilidad actual de publicación en web y redes sociales, reduce una característica histórica del radiodrama, que era su efimeridad por la transmisión por onda. El radiodrama actual está pensado para escucharse, y también para reescucharse, y para que quede como archivo fácilmente accesible de la historia de cada momento. $Y$ una buena noticia para los temerosos: que aparezca en una web, no implica que deje de tratarse de radio: "El concepto de radio no debe ceñirse exclusivamente a las ondas hertzianas, como a veces se pretende; ni siquiera a la difusión por satélite o por cable. La radio se encuentra también en las experimentaciones que se efectúan dentro de Internet" (Cebrián, 2008, p. 13).

Coproducción a distancia. Otra oportunidad que dan las TIC al radiodrama es la posibilidad de coproducción a distancia. Estamos a un correo electrónico de aunar voluntades y eso agiganta nuestras posibilidades creativas como nunca antes: hoy podemos pensar no solo cualquier historia a ser contada, sino contar con cualquier sonido, con cualquier voz, y producirlo con quien queramos. Así, se inaugura una época que de ser bien aprovechada, dejará para el futuro producciones muy interesantes que recuperen, a través de la ficción, la historia del presente y las múltiples miradas regionales sobre lo que nos sucede.

\section{4) Hibridación de géneros.}

Hay que señalar también que las clasificaciones en géneros se flexibilizan. La esquemática clasificación que hicimos al comienzo del presente texto, nos servirá para subvertirla, pensar nuevas formas y combinaciones. La tendencia histórica de la radio de encasillar contenidos dentro del recuadro al que deben pertenecer, en la actualidad se relativiza. Por todas las posibilidades antes expresadas, y por la historia y desarrollo de la radio y el radiodrama, la tendencia está dada hacia la exploración. De este modo, encontraremos herramientas de la ficción integradas a contenidos documentales, periodísticos, noticiosos, musicales, etc. Como lo mencionábamos en el caso de herramientas como la dramatización y la recreación, hoy la ficción radiofónica participa como un agente más dentro de ejemplos muy fructíferos de collage radiofónico (Godínez Galay, 2014). En el collage contamos con materias de distinto color y textura, que son combinadas para originar una nueva forma. Así como en el caso del collage en plástica, donde contamos con óleo, témpera, acuarela, tinta y papel de color; en la radio tenemos la entrevista, la música, el testimonio, el audio histórico, el radioarte, y expresiones de la ficción, que originan un contenido que bien puede designarse como radiodrama, bien como documental sonoro, bien como programa radiofónico. Lo importante es que en la actualidad, la ficción sonora se resignifica y 
participa de la tendencia muy sana a la hibridación de géneros, que contribuye a hacer una radio actual, dinámica, entretenida, interesante y bella. $Y$ que la apoyatura en la facilidad que pueden brindar las TIC, la hacen hoy aún más posible, y necesaria si nos queremos destacar en el mar de contenidos disponibles.

\section{5) Narrativas transmedia.}

Hay que mencionar una tendencia actual fuertemente enfocada en las narrativas transmedia, donde puede y debe participar la ficción sonora. ¿De qué se trata todo esto? Entendemos como narrativas transmedia a aquellas historias, de ficción o no, que son contadas a través de múltiples soportes, algo decididamente fortalecido a partir de la masificación de Internet. En palabras de Carlos Scolari, se trata de "un tipo de relato en el que la historia se despliega a través de múltiples medios y plataformas de comunicación y en el cual una parte de los consumidores asume un rol activo en ese proceso de expansión" (Albarello, 2013, p. 247).

Podemos mencionar distintas formas de lo transmedia. Por un lado, aquellas historias contadas en varios soportes, que mantienen el hilo narrativo en uno de ellos, y ofrecen complementos en los otros, pero que si no se leen no afecta la comprensión de la historia central (por ejemplo, una novela por entregas a través de una web, que linkee a menudo a fotos, videos, podcasts, o incluso a alguna intervención en la vía pública, pero que si no se accede a ninguno de esos complementos, la historia puede disfrutarse igual).

Por otro lado, la idea de la traducción de un soporte a otro, y en donde la historia continúe en alguno de esos soportes. Por ejemplo, una novela en libro, que luego es retomada por una película, pero en donde la historia va más allá de adonde llega la historia en el libro, y un videogame que retoma el mundo narrativo creado por el libro, pero que cuenta dentro de él otros aspectos de la historia no previstos por ese libro.

Hay que señalar que la radio no está tan presente en esta moda de lo transmedia, lo que configura dos cuestiones. Por un lado, el peligro de quedar relegada de las posibilidades para contar historias; que la fascinación por lo transmedia atropelle a la radio. Y por el otro, que debemos pensar en la posibilidad de que se empiecen a crear historias que tengan componentes transmedia, pero cuyo eje sea la radio y concretamente el radiodrama. Esto es visto como un desafío actual y hacia el futuro: que la radio no pierda pisada frente a la vorágine de lo transmedia, y que a la vez, participar de esta moda no suponga perder 
su esencia o su fuerza para contar historias, tan bien ejemplificada por las múltiples formas del radiodrama en la historia. Que la radio se ensanche hacia nuevos mundos transmedia a través de las TIC, pero que no deje de ser radio, para seguir aprovechando sus características y su fuerza.

\section{Radiodramas actuales en América Latina}

Con el correr de los años, se ha diversificado y multiplicado la presencia del radiodrama en América Latina. Revisaremos a continuación algunos casos interesantes de este resurgir en la región, que ejemplifican los conceptos anteriormente vertidos en cuanto a la multiplicidad e hibridación de géneros y subgéneros, y a las posibilidades y necesidades que el nuevo entorno digital habilita.

\section{1) Mil sonidos en un golpe}

Mil sonidos en un golpe cuenta la historia del día del golpe de Estado a Salvador Allende en Chile, pero sobre todo desde el protagonismo que tuvieron la radio y el sonido en esa jornada ${ }^{2}$.

Es presentado como un radiofilm o un documental sonoro. Radiofilm porque si bien puede clasificarse como radioteatro unitario, su construcción narrativa, su apoyatura sonora en determinadas escenas, y sus "cámaras", recuerdan al cine. También es documental, porque utiliza sonidos reales de archivo, que combinados con dramatizaciones hacen de este contenido un buen ejemplo de la técnica de collage radiofónico, donde la combinatoria de distintas materias sonoras construye algo nuevo y original que a veces escapa a las clasificaciones.

Asimismo, es buen ejemplo de lo que mencionábamos respecto de las TIC. Por un lado, porque si bien es una obra larga, de más de una hora, también se publicaron dos versiones adicionales: una pensada para las emisoras que quieran programarlo (es decir, en dos bloques que sumados hacen unos 50 minutos, ideal para programar con las tandas publicitarias), y otra pensada para programar y para escuchas individuales online o vía descarga (cuatro capítulos de alrededor de 15 minutos). $Y$ por otro lado, porque para su producción fueron empleadas las TIC. Este contenido es una coproducción entre el

2 En http://cpr.org.ar/2013/09/mil-sonidos-en-un-golpel 
Centro de Producciones Radiofónicas de Buenos Aires, la radio Juan Gómez Millas de la Universidad de Chile y la organización ECO-Educación y Comunicaciones de Chile. El guión se hizo en Buenos Aires, fue corregido en Santiago, las voces se grabaron en Santiago, las entrevistas y parte de la edición también; y el resto de la edición fue hecha en Buenos Aires. A su vez, su divulgación se hizo casi enteramente por Internet, de donde luego las radios interesadas lo tomaron para emitir. El programa ganó el primer lugar de la categoría de radiodrama del concurso de producciones de la Bienal Internacional de Radio México 2014, y todo fue hecho a costo cero.

\section{2) Agua que no has de temer}

Este radioteatro unitario fue producido en Radio Nacional de Colombia ${ }^{3}$. Narra historias de amor a distancia, para lo cual fue necesario grabar voces de distintas nacionalidades y paisajes sonoros de distintas ciudades. Entonces, hubo actores que no se conocieron, grabaron sus partes por separado (en Argentina, en distintas regiones de Colombia y en España), y productores que aportaron grabaciones de sonidos reales de distintos países de Iberoamérica por los que la historia transcurre. Es otro buen ejemplo de cómo puede fortalecerse la coproducción a distancia, y cómo se pueden combinar sonidos para generar un contenido innovador. Como curiosidad, las TIC no solo están presentes en la producción, sino que son parte de la historia (Skype está presente en la ficción como una forma de acercar a los amantes lejanos, a la vez que en la realidad fue usado para los ensayos).

\section{3) Cuando vuelvas del olvido}

Otro ejemplo de coproducción a distancia, esta vez entre Radio UNAM de México y las radios de UNER (Universidad Nacional de Entre Ríos). Estructuralmente, se trata de una radionovela en 32 capítulos, y cada uno de ellos cuenta al comienzo con un resumen del capítulo anterior, fundamental para buscar la comprensión de la historia si su emisión es semanal, y si su escucha online es esporádica. Narrativamente, se cuenta la historia de la dictadura argentina, los exilios a México, y los hijos de desaparecidos apropiados. Para la producción, generaron equipos en ambos países, y mantuvieron comunicaciones a diario. Para llevar adelante la coproducción se pusieron de acuerdo previamente en las estéticas y en algunos sonidos concretos para unificar. El criterio acordado fue "generar una estética donde la premisa fuera <cine sonoro〉. Que todo se resolviera con audio, y además que en

3 En http://www.senalradionica.gov.co/noticias/agua-que-no-has-de-temer 
el montaje se pudieran dar destellos de radioarte sin que se perdiera la trama"4. Además, incluye elementos transmedia, ya que no solo cuenta con una página web especialmente diseñada ${ }^{5}$, sino que las cartas mencionadas en el relato, fueron recreadas en papel, añejadas y subidas a la web como condimento estético.

\section{Conclusiones}

El radiodrama actual en América Latina se mueve entre tres coordenadas: su efectiva existencia, la oportunidad y el desafío. $\mathrm{Y}$ está atravesado a su vez por los límites y potencialidades que le brindan las TIC. Comprender que el radiodrama como ningún otro género apela tanto a lo racional como a lo emocional, permitirá fortalecer sus usos con fines sociales, a la vez que tomar cada vez más riesgos estéticos.

Como vimos, el género no solo está vivo, sino que tiene posibilidades de potenciarse aún más. Esta vez, con nuevos objetivos que exceden el mero entretenimiento, ya que se agrega lo educativo, lo social, lo cultural. Hoy por hoy hay más lugar para la experimentación, tanto en la hibridación de géneros, como en cuanto a posibilidades estéticas y de divulgación. Las TIC, capaces de abaratar costos, facilitar la producción, agilizarla, y potenciar la coproducción a distancia, un registro sonoro más cuidadoso, y la producción independiente, son una oportunidad inigualable para el género. Asimismo, la posibilidad producir sin la necesidad excluyente de obtener rédito económico, hoy por hoy pone al radiodrama como una herramienta útil para temas sociales.

Debemos reconocer al radiodrama como un género diverso, rico, con muchas posibilidades narrativas. Solo se trata de explorar, salirse de lo obvio. Utilizarlo para hacer una radio distinta, dinámica, entretenida e interesante. Cuánto más sepamos acerca de las múltiples posibilidades que da la ficción en radio, mejor las podremos utilizar.

Comprender ese abanico nos permitirá encarar de forma más contundente el proceso actual en el que todo es atravesado por las TIC. No se trata de asustarse y pensar que el radiodrama muere con la Internet. Todo lo contrario: hoy necesitamos de la ficción sonora para otros fines: sensibilizar, informar, educar. Y claro, entretener también. Sin perder de vista las características específicas del radiodrama, que siguen vigentes y

4 Uno de sus productores en México, Iván González, en entrevista para este artículo.

5 http://www.cuandovuelvasdelolvido.net 
pueden tomar mayor fuerza. Pues bien, la idea es reconocer todas sus posibilidades narrativas y tener presente que una inteligente utilización de las posibilidades que dan las tecnologías nos permitirán concretar aquel anhelo democratizador que siempre se queda en potencialidad: abaratar costos, facilitar la producción, multiplicar esfuerzos, expresarse en la arena pública. Y siempre sin dejar de pensar en ofrecer contenidos originales. Hoy existen formas cada vez más efectivas en las que las TIC y el radiodrama se realimentan, se potencian y junto con la creatividad de los productores y las historias que nuestra región necesita contarse, permitirán una renovación de fuerzas del medio radiofónico.

Referencias

Albarello, F. (2013). Carlos Scolari. Narrativas transmedia: cuando todos los medios cuentan. Austral Comunicación. Volumen 2, número 2. (pp. 247-249). Buenos Aires: Universidad Austral.

Camacho, L. (2007). El radioarte. Un género sin fronteras. México D.F.: Trillas.

Carlón, M., y Scolari, C. (2009). El fin de los medios masivos. Buenos Aires: La Crujía.

Castañeda, M. (2011). Escuchar(nos). México D.F.: Taurus.

Cebrián Herreros, M. (2008). La radio en Internet. Buenos Aires: La Crujía.

Godinez Galay, F. (2011). El radiodrama en la comunicación de mensajes sociales. Buenos Aires: Ediciones del Jinete Insomne.

Godinez Galay, F. (2012). ¿Puede el radioarte tener fines sociales?. Buenos Aires: Centro de Producciones Radiofónicas. Recuperado el 2 de diciembre de 2014 desde http://cpr.org.ar/2012/06/puede-elradioarte-tener-fines-sociales/

Godinez Galay, F. (2014). Nuevas estéticas en la radio social e independiente. Bogotá: Centro de Competencia en Comunicación, Fundación Friedrich Ebert. Recuperado el 2 de diciembre de 2014 desde http://www.fesmedia-latin-america.org/uploads/media/Perspectivas_2.2014___Nuevas_ est\%C3\%A9ticas_en_la_radio_social_e_independiente.pdf

Godinez Falay, F.y Binder, I. (2012). Comunicar o no ser. Vinculaciones entre el derecho a la comunicación, la cultura libre y el copyleft. Bogotá: Centro de Competencia en Comunicación, Fundación Friedrich Ebert. Recuperado el 3 de diciembre de 2014 desde http://www.fesmedia-latin-america.org/uploads/ media/Comunicar_o_no_ser.pdf

Hall, S. (1994). Codificar y decodificar. En Entel, Alicia, Teorías de la Comunicación (pp. 176-187). Buenos Aires: Docencia.

Hall, S. (1998). El problema de la ideología: marxismo sin garantías. En revista Doxa, año IX, número 18. Buenos Aires.

Holgado, A. (2013). Identidad sonora en tiempos de intermedia. Buenos Aires: Ciccus.

Larson Guerra, S. (2012). Pensar el sonido. México D.F:: UNAM.

López Vigil. J. (1997). Manual urgente para radialistas apasionadas y apasionados. Quito: Ciespal. 
COMUNICACIÓN Y MEDIOS № 31 (2015). Instituto de la Comunicación e Imagen, ICEl, Universidad de Chile. ISSN 0719-1529

Merleau-Ponty, M. (1957). Fenomenología de la percepción. Ciudad de México: Fondo de Cultura Económica.

Piscitelli, A. (2011). Creadores y autores en el mundo digital. En Memorias de la 8a Bienal Internacional de Radio (pp. 65-79). Ciudad de México: Radio Educación.

Ulanovsky, C., Merkin, M., Panno, J.y Tijman, G. (2004). Días de radio (1960-1995). Buenos Aires: Emecé. 